\title{
Assessment of the correlation between TIMP4 SNPs and schizophrenia and autism spectrum disorders
}

\author{
SUNG-VIN YIM ${ }^{1}$, SU KANG KIM ${ }^{2}$, HAE JEONG PARK ${ }^{2}$, HYE SOOK JEON ${ }^{2}$, BYUNG CHUL JO ${ }^{2}$, \\ WON SUB KANG ${ }^{3}$, SANG MIN LEE ${ }^{3}$, JONG WOO KIM ${ }^{3}$ and JOO-HO CHUNG ${ }^{2}$ \\ ${ }^{1}$ Department of Clinical Pharmacology; ${ }^{2}$ Department of Pharmacology, Kohwang Medical Research Institute; \\ ${ }^{3}$ Department of Neuropsychiatry, School of Medicine, Kyung Hee University, Seoul 130-702, Republic of Korea
}

Received May 16, 2012; Accepted October 11, 2012

DOI: $10.3892 / \mathrm{mmr} .2012 .1221$

\begin{abstract}
Tissue inhibitors of metalloproteinases (TIMPs) are involved in synaptic plasticity, neuronal cell differentiation and neuroprotection in the central nervous system. To investigate whether TIMP4 polymorphisms are associated with schizophrenia and autism spectrum disorders (ASDs), 480 patients (schizophrenia, $\mathrm{n}=287$; ASDs, $\mathrm{n}=193$ ) and 296 controls were enrolled. Clinical symptoms of schizophrenia and ASDs were assessed using the operation criteria checklist for psychotic illness (OPCRIT) and Childhood Autism Rating Scale (CARS), respectively. One promoter single nucleotide polymorphism (SNP; rs 3755724, -55C/T) and one exonic SNP (rs17035945, 3'-untranslated region) were selected. SNPStats and SNPAnalyzer Pro programs were used to calculate odds ratios. Multiple logistic regression models were performed to analyze the genetic data. Based on the results, these two SNPs were not associated with schizophrenia and ASD. In the analysis of clinical features of schizophrenia, rs3755724 was nominally associated with schizophrenia with poor concentration $(\mathrm{P}=0.044$ in the codominant 2 model, $\mathrm{P}=0.041$ in the log-additive model and $\mathrm{P}=0.043$ in allele frequency). These results suggest that TIMP4 is not associated with the development of schizophrenia and ASD in the population studied.
\end{abstract}

Correspondence to: Professor Jong Woo Kim, Department of Neuropsychiatry, School of Medicine, Kyung Hee University, 1 Hoegi-dong, Dongdaemun-ku, Seoul 130-702, Republic of Korea E-mail: psyjong@gmail.com

Professor Joo-Ho Chung, Department of Pharmacology, School of Medicine, Kyung Hee University, 1 Hoegi-dong, Dongdaemun-ku, Seoul 130-702, Republic of Korea

E-mail: jhchung@khu.ac.kr

Abbreviations: TIMP4, tissue inhibitor of metalloproteinase 4; OPCRIT, operation criteria checklist for psychotic illness; SNP, single nucleotide polymorphism; HWE, Hardy-Weinberg equilibrium; LD, linkage disequilibrium

Key words: tissue inhibitor of metalloproteinase 4, OPCRIT, schizophrenia, autism spectrum disorders, single nucleotide polymorphism, Korean

\section{Introduction}

Tissue inhibitors of metalloproteinases (TIMPs) inhibit the activity of matrix metalloproteinases (MMPs), a family of zinc-dependent endopeptidases, and are important in tissue remodeling of the extracellular matrix (ECM) (1). TIMPs are also involved in immune response, inflammatory process, wound healing, angiogenesis and tumorigenesis (2-4). In the central nervous system, the TIMP/MMP system is correlated with synaptic plasticity and neuronal cell differentiation $(5,6)$. TIMPs consist of TIMP1, TIMP2, TIMP3 and TIMP4. The inhibitors are 23-26 kDa proteins and possess 12 cysteine residues that form 6 sulfide bridges. However, TIMPs differ in solubility and regulation of expression. TIMP1, TIMP2 and TIMP4 are present in soluble forms, while TIMP3 is bound to the matrix. TIMP1, TIMP3 and TIMP4 expression is inducible, whereas TIMP2 expression is constitutive $(7,8)$. Previous studies have demonstrated that TIMP4 mRNAs are localized to the brain, heart, ovary and skeletal muscle, suggesting that the expression pattern of TIMP4 differs from that of other TIMPs. This has led to the hypothesis that TIMP4 is a significant tissue-specific regulator of tissue remodeling $(9,10)$.

With regard to genetics and molecular biology, there is a noteworthy phenomenon between the TIMP and the synapsin (SYN) gene families. TIMP1 is located within an intron of the SYN1 gene (Xp11.23). TIMP3 and TIMP4 are also located within an intronic region of $S Y N 3$ and $S Y N 2$ (22q12.3 and 3p25), respectively. TIMP2 is separately located on $17 \mathrm{q} 25$, regardless of the chromosomal sites of the $S Y N$ gene family (http://www. ncbi.nlm.nih.gov/gene). SYNs are important in synaptogenesis, neuronal development and neurotransmitter release $(11,12)$, and they are implicated in the pathogenesis of several neuropsychiatric diseases, including schizophrenia and autism spectrum disorders (ASDs) $(13,14)$. However, the correlations and interactions between TIMPs and SYNs remain obscure.

Immune and inflammation systems are also implicated in the pathogenesis of neurodegenerative diseases and psychiatric diseases (15-17). The TIMP/MMP expression ratios have been associated with Alzheimer's and Parkinson's diseases $(18,19)$. Previously, Berretta (20) proposed that ECM abnormalities may contribute to the pathophysiology of schizophrenia. The present study explored the correlation between TIMP4 polymorphisms and schizophrenia, as well as ASDs in the Korean population. 


\section{Subjects and methods}

Subjects and clinical phenotypes. A total of 480 patients (schizophrenia, $\mathrm{n}=287$; ASDs, $\mathrm{n}=193$ ) and 296 healthy control subjects were recruited. The schizophrenia group comprised 189 males (mean age, $42.0 \pm 10.9$ years) and 98 females $(42.8 \pm 10.8)$ and the ASD group consisted of 177 males (15.4 \pm 4.8$)$ and 16 females (14.1 \pm 3.1$)$. The control group comprised 142 males (39.7 \pm 5.7$)$ and 154 females (33.4 \pm 6.3$)$. Patients were enrolled among participants who visited the Departments of Neuropsychiatry in the East-West Neomedical Center and Kyung Hee Medical Center (Seoul, Korea). Patients were diagnosed with schizophrenia and ASDs by at least two well-trained psychiatrists, according to the Diagnostic and Statistical Manual of Mental Disorders (4th edition), using available historical information from interviews and clinical records. Subjects enrolled into the control group were assessed as mentally healthy through a general health examination program. Participants with any neurological diseases and psychiatric disorders were excluded.

In the analysis of clinical symptoms of schizophrenia and ASDs, detailed clinical features were confirmed by cliniclans. Schizophrenia patients were classified into 4 subgroups, using the operation criteria checklist for psychotic illness (OPCRIT): poor concentration, persecutory delusion, auditory hallucination and affective disturbances. ASD patients were divided into 2 subgroups, according to the scores of the Childhood Autism Rating Scale (CARS), using a cut-off score of 30 to diagnose ASDs: $<37$ and $\geq 37$ scores (Table I). The ASD group contained 12 Asperger's disorder (11 males/1 female), 34
Table I. Clinical characteristics of study population.

\begin{tabular}{lccc}
\hline Characteristic & Schizophrenia & ASDs & Control \\
\hline Total no. of subjects & 287 & 193 & 296 \\
Male/female (n) & $189 / 98$ & $177 / 16$ & $142 / 154$ \\
Age (mean \pm SD, years) & $42.7 \pm 10.8$ & $15.3 \pm 4.7$ & $36.4 \pm 6.8$ \\
Schizophrenia (n) & & & \\
Poor concentration & & & \\
Absent & 119 & & \\
Present & 168 & & \\
Persecutory delusion & & & \\
Absent & 128 & & \\
Present & 159 & & \\
Auditory hallucination & & & \\
Absent & 138 & & \\
Present & 149 & & \\
Affective disturbances & & & \\
Absent & 60 & & \\
Present & 227 & & \\
ASDs (n) & & & \\
CARS score & & & \\
$<37$ & & 62 & \\
$\geq 37$ & & 131 & \\
\hline
\end{tabular}

ASDs, autism spectrum disorders; CARS, childhood autism rating scale; SD, standard deviation.

Table II. Genotype and allele frequencies of TIMP4 SNPs in patients with schizophrenia and control subjects.

\begin{tabular}{|c|c|c|c|c|c|c|c|c|}
\hline \multirow[b]{2}{*}{ SNP } & \multirow[b]{2}{*}{ Type } & \multicolumn{2}{|c|}{ Control } & \multicolumn{2}{|c|}{ SPR } & \multirow[b]{2}{*}{ Model } & \multirow[b]{2}{*}{ OR $(95 \% \mathrm{CI})$} & \multirow[b]{2}{*}{ P-value } \\
\hline & & $\mathrm{n}$ & $\%$ & $\mathrm{n}$ & $\%$ & & & \\
\hline & Genotype & & & & & & & \\
\hline rs3755724 & $\mathrm{T} / \mathrm{T}$ & 93 & 31.4 & 98 & 34.1 & Codominant1 & $0.91(0.61-1.36)$ & 0.65 \\
\hline \multirow[t]{8}{*}{$-55 \mathrm{C} / \mathrm{T}$} & $\mathrm{T} / \mathrm{C}$ & 140 & 47.3 & 134 & 46.7 & Codominant2 & $0.86(0.53-1.41)$ & 0.55 \\
\hline & $\mathrm{C} / \mathrm{C}$ & 63 & 21.3 & 55 & 19.2 & Dominant & $0.90(0.62-1.30)$ & 0.57 \\
\hline & & & & & & Recessive & $0.91(0.59-1.40)$ & 0.67 \\
\hline & & & & & & Log-additive & $0.93(0.73-1.18)$ & 0.54 \\
\hline & Allele & & & & & & & \\
\hline & $\mathrm{T}$ & 326 & 55.1 & 330 & 57.5 & & 1.00 & \\
\hline & $\mathrm{C}$ & 266 & 44.9 & 244 & 42.5 & & $0.91(0.72-1.14)$ & 0.40 \\
\hline & Genotype & & & & & & & \\
\hline rs17035945 & $\mathrm{C} / \mathrm{C}$ & 217 & 73.3 & 213 & 74.2 & Codominant1 & $0.92(0.61-1.38)$ & 0.67 \\
\hline 3'-UTR & $\mathrm{C} / \mathrm{T}$ & 73 & 24.7 & 68 & 23.7 & Codominant 2 & $1.00(0.28-3.51)$ & 1.00 \\
\hline \multirow[t]{6}{*}{$\mathrm{C} / \mathrm{T}$} & $\mathrm{T} / \mathrm{T}$ & 6 & 2.0 & 6 & 2.1 & Dominant & $0.92(0.62-1.37)$ & 0.69 \\
\hline & & & & & & Recessive & $1.02(0.29-3.57)$ & 0.97 \\
\hline & & & & & & Log-additive & $0.94(0.66-1.34)$ & 0.73 \\
\hline & Allele & & & & & & & \\
\hline & $\mathrm{C}$ & 507 & 85.6 & 494 & 86.1 & & 1.00 & \\
\hline & $\mathrm{T}$ & 85 & 14.4 & 80 & 13.9 & & $1.00(0.70-1.34)$ & 0.84 \\
\hline
\end{tabular}

P-values were evaluated from logistic regression analysis after adjusting for age and gender. TIMP4, tissue inhibitor of metalloproteinase 4; SNP, single nucleotide polymorphism; SPR, schizophrenia; UTR, untranslated region; OR, odds ratio; CI, confidence interval. 
Table III. Genotype and allele frequencies of TIMP4 SNPs in schizophrenia without poor concentration (-) and schizophrenia with poor concentration $(+)$.

\begin{tabular}{|c|c|c|c|c|c|c|c|c|c|}
\hline \multirow[b]{2}{*}{ SNP } & \multirow[b]{2}{*}{ Type } & \multicolumn{4}{|c|}{ Poor concentration } & \multirow[b]{2}{*}{ Model } & \multirow[b]{2}{*}{ OR $(95 \% \mathrm{CI})$} & \multirow[b]{2}{*}{ P-value } & \multirow{2}{*}{$\begin{array}{c}\text { Fisher's } \\
\text { exact } \\
\text { test } \\
\text { P-value }\end{array}$} \\
\hline & & $\mathrm{n}$ & $\%$ & $\mathrm{n}$ & $\%$ & & & & \\
\hline & Genotyp & & & & & & & & \\
\hline rs3755724 & $\mathrm{T} / \mathrm{T}$ & 34 & 28.6 & 64 & 38.1 & Codominant 1 & $0.72(0.42-1.23)$ & 0.22 & \\
\hline \multirow[t]{8}{*}{$-55 \mathrm{C} / \mathrm{T}$} & $\mathrm{T} / \mathrm{C}$ & 57 & 47.9 & 77 & 45.8 & Codominant 2 & $0.50(0.25-0.98)$ & 0.044 & \\
\hline & $\mathrm{C} / \mathrm{C}$ & 28 & 23.5 & 27 & 16.1 & Dominant & $0.64(0.39-1.07)$ & 0.08 & \\
\hline & & & & & & Recessive & $0.61(0.33-1.10)$ & 0.10 & \\
\hline & & & & & & Log-additive & $0.71(0.51-0.99)$ & 0.041 & \\
\hline & Allele & & & & & & & & \\
\hline & $\mathrm{T}$ & 125 & 52.5 & 205 & 61.0 & & 1.00 & & \\
\hline & $\mathrm{C}$ & 113 & 47.5 & 131 & 39.0 & & $0.71(0.51-0.10)$ & 0.043 & \\
\hline & Genotyp & & & & & & & & \\
\hline rs17035945 & $\mathrm{C} / \mathrm{C}$ & 86 & 72.3 & 127 & 75.6 & Codominant 1 & $0.85(0.49-1.49)$ & 0.58 & \\
\hline 3'-UTR & $\mathrm{C} / \mathrm{T}$ & 30 & 25.2 & 38 & 22.6 & Codominant 2 & $0.67(0.13-3.40)$ & 0.63 & 0.69 \\
\hline \multirow[t]{6}{*}{$\mathrm{C} / \mathrm{T}$} & $\mathrm{T} / \mathrm{T}$ & 3 & 2.5 & 3 & 1.8 & Dominant & $0.84(0.49-1.43)$ & 0.52 & \\
\hline & & & & & & Recessive & $0.69(0.14-3.52)$ & 0.66 & 1.00 \\
\hline & & & & & & Log-additive & $0.84(0.52-1.36)$ & 0.48 & \\
\hline & Allele & & & & & & & & \\
\hline & $\mathrm{C}$ & 202 & 84.9 & 292 & 86.9 & & 1.00 & & \\
\hline & $\mathrm{T}$ & 36 & 15.1 & 44 & 13.1 & & $0.85(0.53-1.36)$ & 0.49 & \\
\hline
\end{tabular}

P-values were evaluated from logistic regression analysis after adjusting for age and gender. Bold numbers indicate significant association. TIMP4, tissue inhibitor of metalloproteinase 4; SNP, single nucleotide polymorphism; UTR, untranslated region; OR, odds ratio; CI, confidence interval.

atypical autism (30 males/4 females) and 147 autistic disorder (136 males/11 females) cases. The present study was conducted in accordance with the guidelines of the Helsinki Declaration and was approved by the Ethics Review Committee of Medical Research Institute, Kyung Hee University Medical Center. Informed consent was obtained from each subject. If the patients were incommunicable, informed consent was obtained from their parents or guardians.

In our case-control study, the mean ages of the schizophrenia and ASDs groups were different. It was extremely difficult to obtain controls similar to the onset age of ASDs. To avoid the possibility of subjects with undetected or subclinical ASDs, healthy subjects aged $>20$ years old were included in the control group. Moreover, adult subjects were used as controls, in case of infant or child diseases $(21,22)$. The gender ratios of the schizophrenia and ASDs groups were also different. Gender ratios of schizophrenia and autism are well-known to be $\sim 1: 1$ (male:female) and 9:1 (male:female), respectively. Therefore, statistical data in this study were analyzed following adjustment for age and gender as covariables.

Single nucleotide polymorphism (SNP) section and genotyping. Two SNPs were selected (rs3755724, -55C/T and rs17035945, 3'-untranslated region) (21). These two SNPs also belong to the intronic SNPs (iSNPs) of SYN2. We searched common SNPs with minor allele frequency $(\mathrm{MAF})>0.05$, using the SNP database of the National Center for Biotechnology Information (http://www.ncbi.nlm.nih.gov/ SNP, BUILD 135). However, no common SNPs were identified in the coding region of TIMP4. Genomic DNAs were extracted from peripheral blood using the Roche DNA Extraction kit (Roche Diagnostics, Indianapolis, IN, USA). PCR was conducted using the primers for each SNP as described previously (21): rs3755724 (sense, 5'-AGAGGCAGACAGAATTA CAACAGGCA-3'; antisense, 5'-ACATGACAGAGTCTCC AGTGAGAAGG-3', 439 bp) and rs17035945 (sense, 5'-CCT GAAGATCAAGCCAGTTCTCC-3'; antisense, 5'-GGAGAGG TAGTACCTATTCTGAG-3', $660 \mathrm{bp}$ ). The genotypes of the two examined SNPs were determined by direct sequencing (Macrogen, Seoul, Republic of Korea). SeqManII software (DNASTAR, Inc., Madison, WI, USA) was used to analyze the sequencing data.

Statistical analysis. Hardy-Weinberg equilibrium (HWE) was calculated using SNPStats (http://bioinfo.iconcologia. net/index.php). SNPStats, SNPAnalyzer Pro (ISTECH, Inc., Goyang, Korea) and SPSS 18.0 (SPSS, Inc., Chicago, IL, USA) programs were used to obtain the odds ratios (ORs), 95\% confidence intervals (CIs) and P-values. The linkage disequilibrium (LD) block was evaluated using Haploview version 4.2 (Daly Lab, Cambridge, MA, USA) and Gabriel's method (23). Multiple logistic regression models were performed to analyze 
Table IV. Genotype and allele frequencies of TIMP4 SNPs in patients with autism spectrum disorders and control subjects.

\begin{tabular}{|c|c|c|c|c|c|c|c|c|c|}
\hline \multirow[b]{2}{*}{ SNP } & \multirow[b]{2}{*}{ Type } & \multicolumn{2}{|c|}{ Control } & \multicolumn{2}{|c|}{ ASDs } & \multirow[b]{2}{*}{ Model } & \multirow[b]{2}{*}{ OR $(95 \% \mathrm{CI})$} & \multirow[b]{2}{*}{ P-value } & \multirow{2}{*}{$\begin{array}{c}\text { Fisher's } \\
\text { exact } \\
\text { test } \\
\text { P-value }\end{array}$} \\
\hline & & $\mathrm{n}$ & $\%$ & $\mathrm{n}$ & $\%$ & & & & \\
\hline & Genotype & & & & & & & & \\
\hline rs3755724 & $\mathrm{T} / \mathrm{T}$ & 93 & 31.4 & 75 & 38.9 & Codominant 1 & $0.24(0.01-7.78)$ & 0.42 & \\
\hline \multirow[t]{8}{*}{$-55 \mathrm{C} / \mathrm{T}$} & $\mathrm{T} / \mathrm{C}$ & 140 & 47.3 & 83 & 43.0 & Codominant2 & $0.16(0.01-4.64)$ & 0.29 & \\
\hline & $\mathrm{C} / \mathrm{C}$ & 63 & 21.3 & 35 & 18.1 & Dominant & $0.20(0.01-3.60)$ & 0.24 & \\
\hline & & & & & & Recessive & $0.30(0.02-5.52)$ & 0.40 & \\
\hline & & & & & & Log-additive & $0.40(0.07-2.12)$ & 0.25 & \\
\hline & Allele & & & & & & & & \\
\hline & $\mathrm{T}$ & 326 & 55.1 & 233 & 60.4 & & 1.00 & & \\
\hline & $\mathrm{C}$ & 266 & 44.9 & 153 & 39.6 & & $0.81(0.62-1.04)$ & 0.10 & \\
\hline & Genotyp & & & & & & & & \\
\hline rs17035945 & $\mathrm{C} / \mathrm{C}$ & 217 & 73.3 & 139 & 72.0 & Codominant1 & $0.25(0.01-4.68)$ & 0.36 & \\
\hline 3'-UTR & $\mathrm{C} / \mathrm{T}$ & 73 & 24.7 & 51 & 26.4 & Codominant2 & $0.01(0.00-\mathrm{NA})$ & NA & 1.00 \\
\hline \multirow[t]{6}{*}{$\mathrm{C} / \mathrm{T}$} & $\mathrm{T} / \mathrm{T}$ & 6 & 2.0 & 3 & 1.6 & Dominant & $0.23(0.01-3.98)$ & 0.28 & \\
\hline & & & & & & Recessive & $0.02(0.00-\mathrm{NA})$ & NA & 1.00 \\
\hline & & & & & & Log-additive & $0.24(0.01-3.85)$ & 0.26 & \\
\hline & Allele & & & & & & & & \\
\hline & $\mathrm{C}$ & 507 & 85.6 & 329 & 85.2 & & 1.00 & & \\
\hline & $\mathrm{T}$ & 85 & 14.4 & 57 & 14.8 & & $1.03(0.72-1.49)$ & 0.86 & \\
\hline
\end{tabular}

P-values were evaluated from logistic regression analysis after adjusting for age and gender. TIMP4, tissue inhibitor of metalloproteinase 4; SNP, single nucleotide polymorphism; ASDs, autism spectrum disorders; UTR, untranslated region; OR, odds ratio; CI, confidence interval; NA, not applicable.

the genetic data: codominant1 (major allele homozygotes vs. heterozygotes), codominant2 (major allele homozygotes vs. minor allele homozygotes), dominant (major allele homozygotes vs. heterozygotes + minor allele homozygotes), recessive (major allele homozygotes + heterozygotes vs. minor allele homozygotes), overdominant (major allele homozygotes + minor allele homozygotes vs. heterozygotes) and log-additive (major allele homozygotes vs. heterozygotes vs. minor allele homozygotes) (24). If the number of subjects was $<5$, the $\mathrm{P}$-value was reevaluated by Fisher's exact test. $\mathrm{P}<0.05$ was considered to indicate a statistically significant difference.

\section{Results}

Genotype analysis in schizophrenia. The genotype and allele frequencies of the two examined SNPs in schizophrenia are shown in Table II. The rs3755724 and rs17035945 SNPs were not associated with the development of schizophrenia. In the analysis of clinical symptoms, the genotype frequency of rs3755724 was significantly different between schizophrenia without poor concentration and schizophrenia with poor concentration $(\mathrm{P}=0.044$ in the codominant 2 model and $\mathrm{P}=0.041$ in the log-additive model). The allele frequency of rs 3755724 was also associated with schizophrenia with poor concentration $(\mathrm{P}=0.043)$. The $\mathrm{C}$ allele frequency of $\mathrm{rs} 3755724$ was lower in the poor concentration (+) group $(38.9 \%)$ than in the poor concentration (-) group (47.5\%; Table III). However, these correlations disappeared following Bonferroni's correction. The two tested SNPs were not correlated with the other clinical phenotypes of schizophrenia, including persecutory delusion, auditory hallucination and affective disturbances (data not shown). These results suggest that rs3755724 and rs17035945 are not associated with schizophrenia in the Korean population.

Genotype analysis in ASDs. In Table IV, the genotype and allele frequencies of rs3755724 and rs17035945 did not contribute to the susceptibility of ASDs. As shown in Table V, these two SNPs were not different between the two subgroups according to the CARS scores (ASDs with $<37$ and ASDs with $\geq 37$ ). Next, we analyzed 177 males with ASDs as the number of females with ASDs was relatively small $(n=16)$. The rs3755724 and rs17035945 SNPs were not associated with male ASDs (data not shown). Finally, we evaluated 136 males with autistic disorder, while excluding females with autistic disorder $(n=11)$, Asperger's disorder $(n=12)$ and atypical autism $(n=34)$. The two tested SNPs did not correlate with the susceptibility and severity of male autistic disorder (data not shown). These results suggest that rs3755724 and rs17035945 are not associated with ASDs in the Korean population.

$L D$. The two examined SNPs were in Hardy-Weinberg equilibrium ( $\mathrm{P}>0.05$, data not shown). Haploview version 4.2 was used to evaluate the LD block between rs3755724 and rs17035945. The LD block in the control group was not made 
Table V. Genotype and allele frequencies of TIMP4 SNPs in ASDs patients according to CARS scores.

\begin{tabular}{|c|c|c|c|c|c|c|c|c|c|}
\hline \multirow[b]{3}{*}{ SNP } & \multirow[b]{3}{*}{ Type } & \multicolumn{4}{|c|}{ CARS score } & \multirow[b]{3}{*}{ Model } & \multirow[b]{3}{*}{ OR $(95 \% \mathrm{CI})$} & \multirow[b]{3}{*}{ P-value } & \multirow{3}{*}{$\begin{array}{c}\text { Fisher's } \\
\text { exact } \\
\text { test } \\
\text { P-value }\end{array}$} \\
\hline & & \multicolumn{2}{|c|}{$<37$} & \multicolumn{2}{|c|}{$\geq 37$} & & & & \\
\hline & & $\mathrm{n}$ & $\%$ & $\mathrm{n}$ & $\%$ & & & & \\
\hline & Genotype & & & & & & & & \\
\hline rs3755724 & $\mathrm{T} / \mathrm{T}$ & 28 & 45.2 & 47 & 35.9 & Codominant 1 & 1.38 (0.71-2.69) & 0.34 & \\
\hline \multirow[t]{8}{*}{$-55 \mathrm{C} / \mathrm{T}$} & $\mathrm{T} / \mathrm{C}$ & 25 & 40.3 & 58 & 44.3 & Codominant 2 & $1.74 \quad(0.71-4.27)$ & 0.23 & \\
\hline & $\mathrm{C} / \mathrm{C}$ & 9 & 14.5 & 26 & 19.8 & Dominant & 1.47 (0.79-2.74) & 0.22 & \\
\hline & & & & & & Recessive & 1.47 (0.64-3.39) & 0.36 & \\
\hline & & & & & & Log-additive & $1.33 \quad(0.87-2.05)$ & 0.19 & \\
\hline & Allele & & & & & & & & \\
\hline & $\mathrm{T}$ & 81 & 65.3 & 152 & 58.0 & & 1.00 & & \\
\hline & $\mathrm{C}$ & 43 & 34.7 & 110 & 42.0 & & $1.36(0.88-2.13)$ & 0.17 & \\
\hline & Genotyp & & & & & & & & \\
\hline rs17035945 & $\mathrm{C} / \mathrm{C}$ & 47 & 75.8 & 92 & 70.2 & Codominant 1 & $1.38 \quad(0.68-2.82)$ & 0.37 & \\
\hline 3'-UTR & $\mathrm{C} / \mathrm{T}$ & 14 & 22.6 & 37 & 28.2 & Codominant 2 & $0.92(0.08-10.73)$ & 0.95 & 1.00 \\
\hline \multirow[t]{6}{*}{$\mathrm{C} / \mathrm{T}$} & $\mathrm{T} / \mathrm{T}$ & 1 & 1.6 & 2 & 1.5 & Dominant & $1.35 \quad(0.67-2.70)$ & 0.39 & \\
\hline & & & & & & Recessive & $0.85 \quad(0.07-9.86)$ & 0.90 & 1.00 \\
\hline & & & & & & Log-additive & $1.28 \quad(0.67-2.43)$ & 0.45 & \\
\hline & Allele & & & & & & & & \\
\hline & $\mathrm{C}$ & 108 & 87.1 & 221 & 84.4 & & 1.00 & & \\
\hline & $\mathrm{T}$ & 16 & 12.9 & 41 & 15.6 & & $1.25(0.67-2.33)$ & 0.48 & \\
\hline
\end{tabular}

P-values were evaluated from logistic regression analysis after adjusting for age and gender. TIMP4, tissue inhibitor of metalloproteinase 4; SNP, single nucleotide polymorphism; ASDs, autism spectrum disorders; CARS, childhood autism rating scale; UTR, untranslated region; OR, odds ratio; $\mathrm{CI}$, confidence interval.

$\left(D^{\prime}=0.644\right.$ and $\left.r^{2}=0.085\right)$. Thus, we did not analyze the haplotypes of these two SNPs.

Sample power. The power of the sample size was estimated using a genetic power calculator (http://pngu.mgh.harvard. $\mathrm{edu} / \sim$ purcell/gpc). The conditions of the sample power were $\alpha=0.05$, risk $=2$-fold and no. of cases $=80 \%$ power. In schizophrenia, the sample power of each SNP was 0.89 for rs 3755724 $(n=218)$ and 0.90 for $r s 17035945(n=214)$. In ASDs, the sample power of each SNP was 0.89 for rs3755724 $(n=150)$ and 0.82 for $\mathrm{rs} 17035945(\mathrm{n}=185)$. Therefore, the number of cases was sufficient to obtain statistical confidence.

\section{Discussion}

Previous studies have reported the role of genetic variants of numerous genes. Numerous studies on the correlation between SNPs of the $M M P$ family and various diseases have been also published, but those of the TIMP family were relatively small. To date, TIMPI SNPs have been shown to be associated with glaucoma, rheumatoid arthritis and abdominal aortic aneurysm (25-27). Genetic variants of TIMP2 are a risk factor for the susceptibility of several diseases, including head and neck cancer, Kawasaki disease and chronic obstructive pulmonary disease (COPD) (28-30). TIMP3 polymorphisms contribute to breast cancer, abdominal aortic aneurysm and age-related macular degeneration (31-33).
Focusing on TIMP4 SNPs, few studies have been identified. Ban et al (21) reported that the C allele of rs3755724 (-55C/T) of TIMP4 was associated with susceptibility to coronary artery lesions of Kawasaki disease and rs17035945 was not. The authors suggest that rs3755724 of TIMP4 may be correlated with the development of Kawasaki disease with coronary artery lesions. As discussed, TIMP4 is located within the intron region of the SYN2 gene. Lee et al (34) reported that rs2279750 and rs308952 (SNPs of TIMP4 and SYN2) were not associated with schizophrenia, but the haplotypes of SYN2 SNPs were associated with schizophrenia. By contrast, a family-based study by Saviouk et al (35) revealed that two SNPs (rs3817004 and ss35528972, now registered rs28897668) of TIMP4 and SYN2 were correlated with schizophrenia susceptibility. The authors identified a marked association between the haplotypes and schizophrenia. The haplotypes were constructed by 6 SNPs (rs99365, rs17035945, rs3817004, ss35528972, rs3755724 and rs931676). One SNP, rs931676, is located in the region of only SYN2. The additional 5 SNPs, including our two tested SNPs (rs3755724 and rs17035945), are located in the region of TIMP4 and SYN2. In this study, rs3755724 and rs17035945 of TIMP4 were not associated with the development of schizophrenia and ASDs. However, the study by Saviouk et al (35) demonstrated a positive association between schizophrenia susceptibility and various SNPs and/or haplotypes, including the two tested SNPs in TIMP4. To confirm these correlations, additional studies of larger cases or other populations should be conducted. 
To date, immunological events focus on the pathogenesis of neurodegenerative diseases and neuropsychiatric disorders. It is well-known that the TIMP/MMP system is important for the immune response and inflammatory process. Although the physical link between the TIMP and the SYN families are evolutionally explained, the functional role and interaction between the two families remain unclear. More detailed genetic and molecular biological studies may reveal a clue to a noteworthy phenomenon between TIMPs and SYNs.

In conclusion, we report that rs3755724 and rs17035945 of TIMP4 are not associated with the development and clinical features of schizophrenia and ASDs in the Korean population.

\section{Acknowledgements}

This study was supported by a grant from the Kyung Hee University (KHU-20071484).

\section{References}

1. Clark IM, Swingler TE, Sampieri CL and Edwards DR: The regulation of matrix metalloproteinases and their inhibitors. Int J Biochem Cell Biol 40: 1362-1378, 2008

2. Bourboulia D and Stetler-Stevenson WG: Matrix metalloproteinases (MMPs) and tissue inhibitors of metalloproteinases (TIMPs): positive and negative regulators in tumor cell adhesion. Semin Cancer Biol 20: 161-168, 2010.

3. Lambert E, Dassé E, Haye B and Petitfrère E: TIMPs as multifacial proteins. Crit Rev Oncol Hematol 49: 187-198, 2004.

4. Pilcher BK, Wang M, Qin XJ, Parks WC, Senior RM and Welgus HG: Role of matrix metalloproteinases and their inhibition in cutaneous wound healing and allergic contact hypersensitivity. Ann NY Acad Sci 878: 12-24, 1999.

5. Candelario-Jalil E, Yang Y and Rosenberg GA: Diverse roles of matrix metalloproteinases and tissue inhibitors of metalloproteinases in neuroinflammation and cerebral ischemia Neuroscience 158: 983-994, 2009.

6. Crocker SJ, Pagenstecher A and Campbell IL: The TIMPs tango with MMPs and more in the central nervous system. J Neurosci Res 75: 1-11, 2004.

7. Gomez DE, Alonso DF, Yoshiji $\mathrm{H}$ and Thorgeirsson UP: Tissue inhibitors of metalloproteinases: structure, regulation and biological functions. Eur J Cell Biol 74: 111-122, 1997.

8. Swarnakar S, Paul S, Singh LP and Reiter RJ: Matrix metalloproteinases in health and disease: regulation by melatonin. J Pineal Res 50: 8-20, 2011.

9. Leco KJ, Apte SS, Taniguchi GT, et al: Murine tissue inhibitor of metalloproteinases-4 (Timp-4): cDNA isolation and expression in adult mouse tissues. FEBS Lett 401: 213-217, 1997.

10. Melendez-Zajgla J, Del Pozo L, Ceballos G and Maldonado V: Tissue inhibitor of metalloproteinases-4. The road less traveled. Mol Cancer 7: 85, 2008.

11. Cesca F, Baldelli P, Valtorta F and Benfenati F: The synapsins: key actors of synapse function and plasticity. Prog Neurobiol 91: 313-348, 2010.

12. Valtorta F, Pozzi D, Benfenati F and Fornasiero EF: The synapsins: multitask modulators of neuronal development. Semin Cell Dev Biol 22: 378-386, 2011.

13. Dyck BA, Beyaert MG, Ferro MA and Mishra RK: Medial prefrontal cortical synapsin II knock-down induces behavioral abnormalities in the rat: examining synapsin II in the pathophysiology of schizophrenia. Schizophr Res 130: 250-259, 2011.

14. Fassio A, Patry L, Congia S, et al: SYN1 loss-of-function mutations in autism and partial epilepsy cause impaired synaptic function. Hum Mol Genet 20: 2297-2307, 2011.
15. Brown AS: The environment and susceptibility to schizophrenia. Prog Neurobiol 93: 23-58, 2011.

16. Chang DM, Su WL and Chu SJ: The expression and significance of intracellular $\mathrm{T}$ helper cytokines in systemic lupus erythematosus. Immunol Invest 31: 1-12, 2002.

17. Garay PA and McAllister AK: Novel roles for immune molecules in neural development: implications for neurodevelopmental disorders. Front Synaptic Neurosci 2: 136, 2010.

18. Lim NK, Villemagne VL, Soon CP, et al: Investigation of matrix metalloproteinases, MMP-2 and MMP-9, in plasma reveals a decrease of MMP-2 in Alzheimer's disease. J Alzheimers Dis 26: 779-786, 2011.

19. Lorenzl S, Albers DS, LeWitt PA, et al: Tissue inhibitors of matrix metalloproteinases are elevated in cerebrospinal fluid of neurodegenerative diseases. J Neurol Sci 207: 71-76, 2003.

20. Berretta S: Extracellular matrix abnormalities in schizophrenia. Neuropharmacology 62: 1584-1597, 2012

21. Ban JY, Yoon KL, Kim SK, Kang S and Chung JH: Promoter polymorphism (rs3755724, $-55 \mathrm{C} / \mathrm{T}$ ) of tissue inhibitor of metalloproteinase 4 (TIMP4) as a risk factor for Kawasaki disease with coronary artery lesions in a Korean population. Pediatr Cardiol 30: 331-335, 2009.

22. Nakanishi K, Sako M, Yata N, et al: A-20C angiotensinogen gene polymorphism and proteinuria in childhood $\operatorname{IgA}$ nephropathy. Pediatr Nephrol 19: 144-147, 2004.

23. Gabriel SB, Schaffner SF, Nguyen H, et al: The structure of haplotype blocks in the human genome. Science 296: 2225-2229, 2002.

24. Kim SK, Park HJ, Lee JS, et al: Association of Niemann-pick disease, type C2 (NPC2) polymorphisms with obesity in Korean population. Mol Cell Toxicol 6: 395-400, 2010.

25. Burkhardt J, Petit-Teixeira E, Teixeira VH, et al: Association of the X-chromosomal genes TIMP1 and IL9R with rheumatoid arthritis. J Rheumatol 36: 2149-2157, 2009.

26. Majsterek I, Markiewicz L, Przybylowska K, et al: Association of MMP1-1607 1G/2G and TIMP1 372 T/C gene polymorphisms with risk of primary open angle glaucoma in a Polish population. Med Sci Monit 17: 417-421, 2011.

27. Thompson AR, Drenos F, Hafez H and Humphries SE: Candidate gene association studies in abdominal aortic aneurysm disease: a review and meta-analysis. Eur J Vasc Endovasc Surg 35: 19-30, 2008.

28. Hegab AE, Sakamoto T, Uchida Y, et al: Association analysis of tissue inhibitor of metalloproteinase2 gene polymorphisms with COPD in Egyptians. Respir Med 99: 107-110, 2005.

29. Furuno K, Takada H, Yamamoto K, et al: Tissue inhibitor of metalloproteinase 2 and coronary artery lesions in Kawasaki disease. J Pediatr 151: 155-160, 2007.

30. O-Charoenrat P and Khantapura P: The role of genetic polymorphisms in the promoters of the matrix metalloproteinase- 2 and tissue inhibitor of metalloproteinase-2 genes in head and neck cancer. Oral Oncol 42: 257-267, 2006.

31. Chen W, Stambolian D, Edwards AO, et al: Genetic variants near TIMP3 and high-density lipoprotein-associated loci influence susceptibility to age-related macular degeneration. Proc Natl Acad Sci USA 107: 7401-7406, 2010.

32. Ogata T, Shibamura H, Tromp G, et al: Genetic analysis of polymorphisms in biologically relevant candidate genes in patients with abdominal aortic aneurysms. J Vasc Surg 41: 1036-1042, 2005.

33. Peterson NB, Beeghly-Fadiel A, Gao YT, et al: Polymorphisms in tissue inhibitors of metalloproteinases- 2 and -3 and breast cancer susceptibility and survival. Int J Cancer 125: 844-850, 2009.

34. Lee HJ, Song JY, Kim JW, et al: Association study of polymorphisms in synaptic vesicle-associated genes, SYN2 and CPLX2, with schizophrenia. Behav Brain Funct 1: 15, 2005.

35. Saviouk V, Moreau MP, Tereshchenko IV, Brzustowicz LM: Association of synapsin 2 with schizophrenia in families of Northern European ancestry. Schizophr Res 96: 100-111, 2007. 